\title{
Systematic review and meta-analysis of the association between childhood physical activity and age at menarche
}

\author{
Lucia Calthorpe (Lucia.calthorpe@ucsf.edu) ${ }^{1,2}$ iD, Soren Brage ${ }^{3}$, Ken K. Ong ${ }^{3,4}$ \\ 1.Department of Public Health and Primary Care, University of Cambridge, Cambridge, UK \\ 2.School of Medicine, University of California at San Francisco, San Francisco, CA, USA \\ 3.MRC Epidemiology Unit, Institute of Metabolic Science, University of Cambridge, Cambridge, UK \\ 4.Department of Paediatrics, University of Cambridge, Cambridge, UK
}

\section{Keywords}

Age at menarche, Athlete, Physical activity, Puberty timing

\section{Correspondence}

$L$ Calthorpe, School of Medicine, University of California at San Francisco, 505 Parnassus Ave, San Francisco, CA 94143, USA.

Tel/Fax: (510) 5908851

Email: Lucia.calthorpe@ucsf.edu

\section{Received}

26 October 2018; revised 11 December 2018 accepted 21 December 2018.

DOI:10.1111/apa.14711
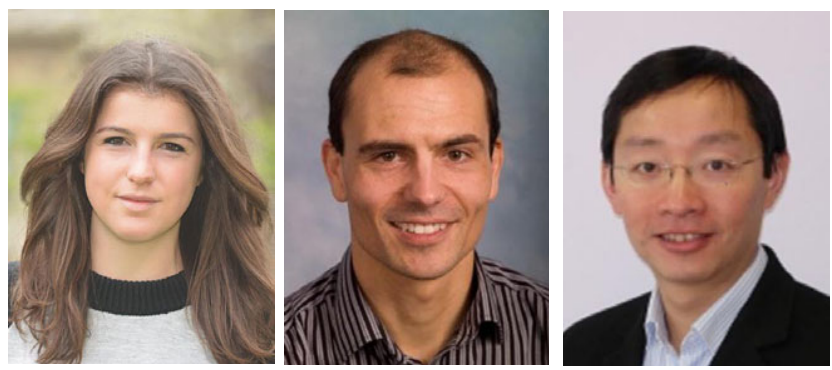

\section{ABSTRACT}

Aim: To systematically appraise and summarise published evidence on the association between childhood physical activity (PA) and subsequent age at menarche (AAM).

Methods: We searched PubMed (1990-2018) for studies that reported the relationship between childhood PA and AAM. We performed tabular synthesis of population-based studies and a random-effects meta-analysis of results of athlete/nonathlete studies.

Results: One randomised controlled trial was identified, in which an intervention to prevent obesity reduced the likelihood of menarche during the two-year study period (relative risk: 0.75, 95\% Cl: 0.66-0.87; $\mathrm{n}=422$ girls). One of five prospective cohort studies (total $\mathrm{n}=4492$ ) reported a significant association between self-reported PA duration and subsequent menarche timing. Four of five historical cohort studies (total $n=89470$ ) reported significant associations between recalled premenarcheal PA and later AAM. Metaanalysis across 12 athlete/nonathlete studies showed that menarche occurred 1.13 years later (95\% Cl: 0.80-1.47) in athletes compared to nonathletes.

Conclusion: These findings suggest that AAM is a behaviourally modifiable trait. However, the quality of reported population-based study evidence is low and estimation of the true relationship between childhood PA and AAM is likely confounded by concomitant changes in diet and lifestyle behaviours.

\section{INTRODUCTION}

Puberty, the process of rapid growth and sexual maturation that separates childhood from adulthood, represents a critical period in normal development. The timing of puberty has been associated with a wide range of later health outcomes. In general, earlier puberty timing is associated with higher risks of adverse health and behavioural outcomes. Short-term outcomes include depression, substance abuse, earlier age at first sexual intercourse, suicide and eating disorders (1-3). Long-term outcomes

\footnotetext{
Abbreviations

AAM, Age at menarche; BMI, Body mass index; HCS, Historical cohort study; PA, Physical activity; PCS, Prospective cohort study; RCT, Randomised control trial.
}

include cardiovascular disease, Type 2 diabetes, breast cancer and all-cause mortality (4-7).

\section{Key Notes}

- This systematic literature review found that the only randomised controlled trial and five of ten cohort studies reported a significant association between premenarcheal physical activity and later age at menarche (AAM), a key measure of puberty timing in girls.

- Meta-analysis across 12 athlete/nonathlete studies showed that menarche occurred 1.13 years later in athletes compared to nonathletes.

- These findings suggest that AAM may be a behaviourally modifiable trait. 
Age at menarche (AAM), a young woman's first menstrual bleed, is a widely used measure of puberty timing because it is a distinct and notable event that is usually wellrecalled (8-10). Widely available data on AAM have been used to demonstrate population-level secular trends towards younger AAM that appear to parallel improvements in socio-economic conditions. In the UK, such secular trends were observed over most of the 20th century and are still detectable in recent birth cohorts (11).

Puberty timing is a multifactorial trait, and a wide range of genetic and environmental determinants have been proposed. Large-scale genetic studies have identified nearly 400 independent genetic variants that are robustly associated with AAM, a trait that clusters within families and has an estimated heritability of 50-70\% (12). AAM has also been associated with several potentially modifiable factors, including prenatal exposures, birthweight, childhood nutrition and body mass index (BMI), socio-economic circumstances and stress and physical activity (PA) $(13,14)$. While delayed puberty in elite athletes has been documented, less attention has been paid to the potential role of moderate PA levels. For example, Yermachenko and Dvornyk's systematic review of nongenetic determinants of AAM identified five papers which demonstrated a potential relationship between high-intensity exercise, largely in combination with nutritional deprivation, and delayed AAM. However, these authors did not explicitly include 'PA' or a similar term in their search (14). Here, we aimed to systematically review the association between PA and AAM, by including findings from both population-based cohorts and athlete versus nonathlete studies.

\section{METHODS}

\section{Literature search}

To identify papers reporting on the relationship between childhood (specifically premenarcheal) PA and subsequent AAM, we conducted a literature search in Medline (Ovid) up to January 25,2017 . The search terms were chosen to be inclusive:

[female*.mp OR girl*.mp] AND

[exp Exercise/OR exercis*.mp. OR physical activit".mp. OR physical activity.mp] AND

[exp Puberty, Precocious/OR exp Menarche/OR menarch".mp. OR exp Puberty/OR exp Sexual Maturation/or sexual maturation*.mp. OR sexual maturity*.mp. OR pubertal $\left.{ }^{*} . \mathrm{mp}\right]$

After exclusion of duplicates, papers published prior to 1990 (in the light of the secular changes in puberty timing), non-English language papers and reviews without primary data, we screened the title and abstract of 908 papers for relevance (Fig. 1). We identified 72 papers describing population-based cohorts and 46 papers on athlete/nonathlete studies to be of potential relevance, and these were reviewed in full text against the exclusion criteria (Tables S1 and S2). Given that early menarche has been shown to lead to subsequent decline in PA (15-17), we excluded cohort studies that did not assess PA prior to menarche. Among athlete/nonathlete studies, we included studies of dancers as a subtype of athlete because of comparable duration and intensity of dance PA. The search was updated on September 7, 2018, but no further relevant studies were identified.

Study quality was assessed using the NIH Quality Assessment Tool for Observational Cohort and Cross-Sectional Studies.

\section{Meta-analysis}

From athlete/nonathlete studies, we extracted data on the between-group difference in AAM. For those studies that did not report this difference, group means and standard deviations for AAM were converted to mean difference $\left(\mu_{1}-\right.$ $\left.\mu_{2}\right)$ and standard error for the difference. Inverse-varianceweighted random-effects meta-analysis was conducted using the metan command in Stata v14.2 (StataCorp LP, College Station, TX, USA).

\section{RESULTS}

\section{Population-based studies}

Population-based studies were further classified by study design: (i) randomised control trials $(\mathrm{RCT}$; $\mathrm{n}=1$ ); (ii) prospective cohort studies (PCS; $\mathrm{n}=5$ ), which assessed PA in premenarcheal girls who were then followed to menarche, or (iii) historical cohort studies (HCS; $n=5$ ), in which PA prior to menarche was recalled in postmenarcheal girls (Tables S2 and S3). Study quality was rated as higher among PCS (range: 7-12) than among HCS (range: 5-7) (Tables S4 and S5). All studies assessed PA using self-reported measures.

The one identified RCT reported that a school-based intervention ('Planet Health'), designed to prevent obesity in premenarcheal girls (age range 10-13 years old; $n=422$ ), reduced the likelihood of menarche occurring during the two-year intervention period $(\mathrm{RR}=0.75,95 \%$ CI: 0.66-0.87) (18). PA was estimated to account for roughly $1 / 3$ of the intervention effect (RR adjusted for $\mathrm{PA}=0.84,95 \%$ CI: 0.74, 0.96). The effect of the intervention on menarche was further attenuated when changes in screen time, BMI and triceps skinfold thickness were controlled for (18).

The five PCS covered diverse geographical areas, ranged in size from $n=167$ to $n=2487$ girls and used a variety of measures of PA (Table 1; Table S2). Weight-adjusted energy expenditure was associated with lower risk of menarche (i.e. later menarche) in one study (Merzenich et al.), but two other studies found no association (table 6 (19-22)). A fourth study (Koo et al.) reported a higher risk of menarche associated with energy expenditure (i.e. earlier menarche) but did not adjust for body weight (21). PA duration was associated with lower risk of menarche in one study (Merzenich et al.), but one other study found no association (Moisan et al.) $(19,22)$. One study (Tehrani et al.) examined a dichotomised measure of PA and found similar mean AAM between active and nonactive girls (23).

The five HCS were mostly European, and sample sizes ranged from 750 to 81438 girls (Tables 2 and S3). PA 


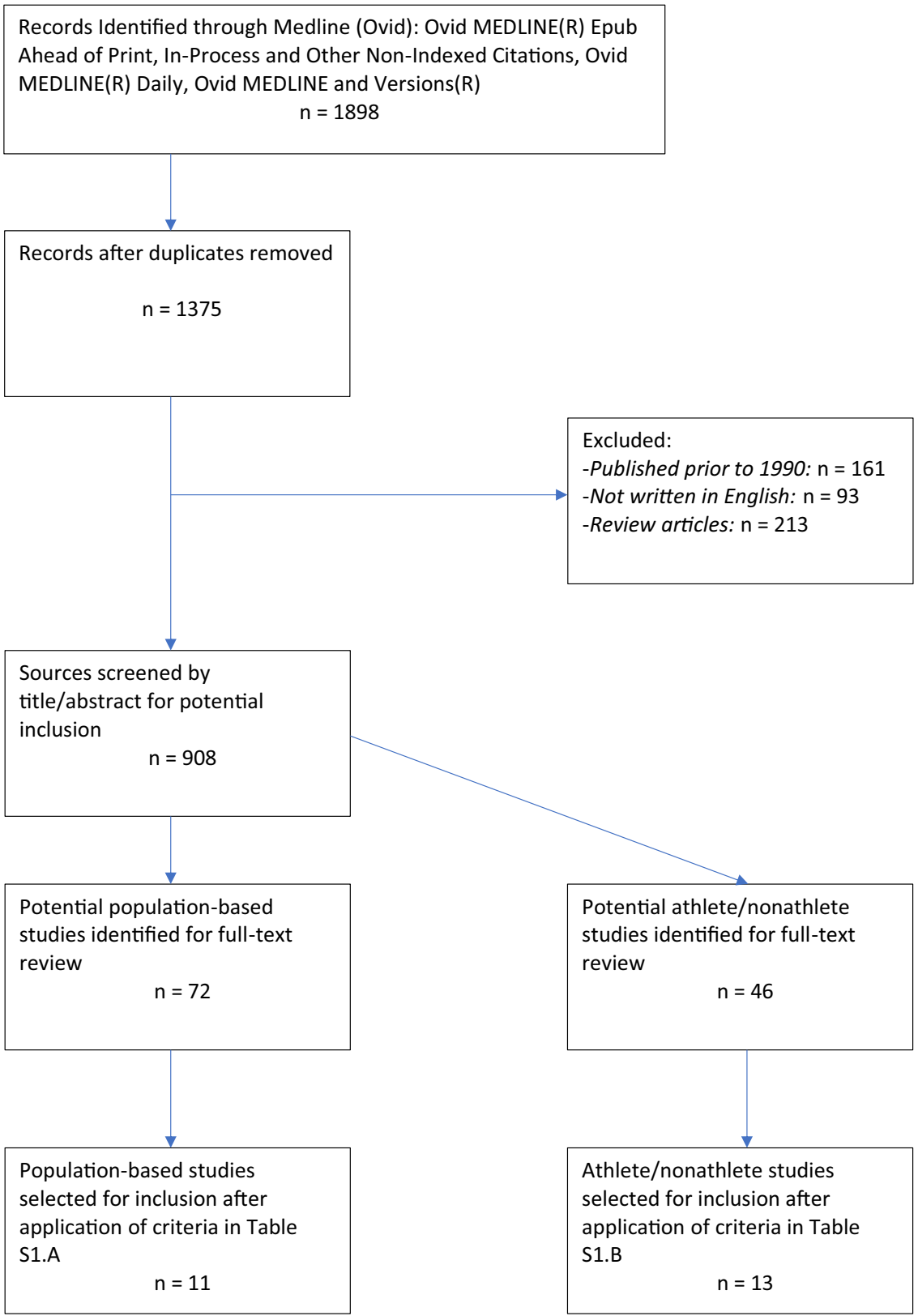

Figure 1 Search strategy flow chart.

duration was associated with later AAM in all three studies that reported this measure, although effect estimates differed widely (24-26). Two studies tested dichotomised PA exposures: one study (Vandeloo et al.) reported that more active girls had significantly later AAM, but the other study found no association (Papadimitriou et al.) $(27,28)$.

\section{Athlete versus nonathlete studies}

Thirteen studies identified athletes (defined by their participation prior to menarche) and compared these to nonathletes with regard to AAM, which was assessed prospectively in two studies and retrospectively in 11 studies (Table S6). Between-group differences in AAM were meta-analysed across studies using random-effects models, excluding one study (Schevchenko et al.), which did not report standard errors or standard deviations for AAM (29).

Overall, menarche occurred 1.13 years (95\% CI: 0.80 1.47) later in athletes compared to nonathletes (Fig. 2). Mean differences ranged from 1.79 years (1.23-2.36; five studies) later in gymnasts compared to nongymnasts to 0.49 years (0.21-0.77; two studies) later in novice (nonelite) athletes compared to nonathletes. High heterogeneity was observed in effect estimates between studies (I-squared: 


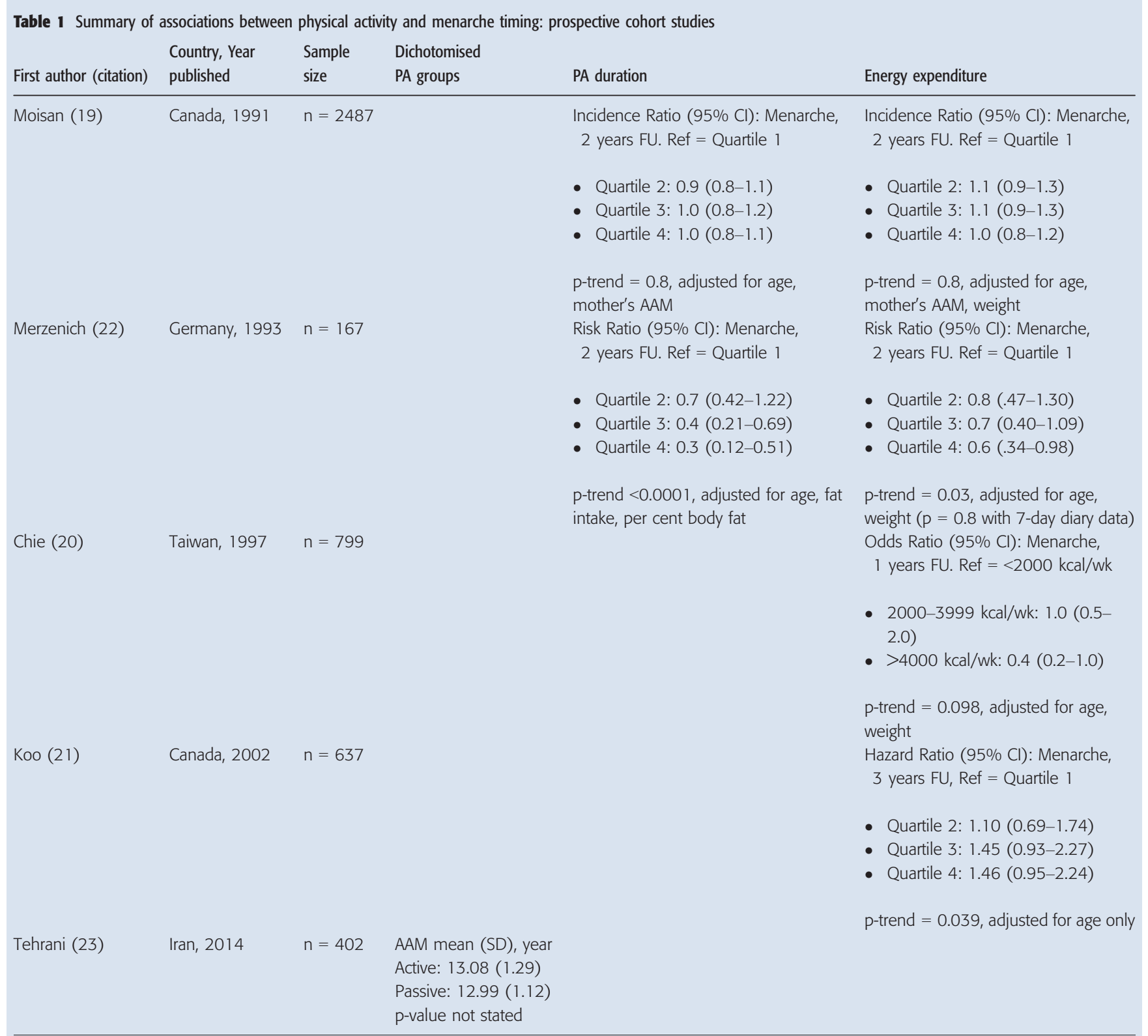

$\mathrm{PA}=$ Physical activity, $\mathrm{AAM}=$ Age at menarche, $\mathrm{FU}=$ Follow-up, Ref $=$ Reference group.

$89.6 \%$ ), but this was less within subgroups of studies of the same athlete type (I-squared: 50.0-57.2\%).

\section{DISCUSSION}

We identified a large number of studies $(n=24)$ reporting on the possible relationship between PA and AAM, however, most used study designs that are considered to provide relatively low levels of evidence. All 13 athlete/nonathlete studies reported a difference in AAM, 4/5 HCS reported a significant association between recalled premenarcheal PA and later AAM, but only 1/5 PCS reported a significant association between premenarcheal PA and later timing of menarche. The one RCT reported a lower likelihood of menarche during the study period in the intervention group.

The two prospective athlete/nonathlete studies found differences in AAM that were of similar size to those athlete/nonathlete studies that recalled AAM, which reduces the likelihood of substantial recall bias. Therefore, the main limitation of these studies, as in all the other types of study considered, is the possibility of confounding due to other differences in behaviour or other attributes between athletes and nonathletes. Across all studies, only one (the PCS by Merzenich et al.) attempted to control for 


\begin{tabular}{|c|c|c|c|c|}
\hline First author (citation) & Country, Year published & Sample size & Dichotomised PA groups & PA duration \\
\hline Veronesi (26) & Italy, 1994 & $n=2930$ & & $\begin{array}{l}\text { Mean Difference (SE): AAM (years) } \\
\text { Ref: Moderate PA (2 h/wk) } \\
\text { - Regular: } 0.35(0.144) \\
\text { - Intense: } 0.66(0.206) \\
\text { p-ANOVA <0.01 }\end{array}$ \\
\hline Chavarro (25) & Colombia, 2004 & $n=3206$ & & $\begin{array}{l}\text { Mean difference }(95 \% \mathrm{Cl}) \text { : AAM } \\
\text { (years) } \\
\text { Ref: Not physically active: } \\
\text { - }<1 \mathrm{~h} / \mathrm{d}: 0.05(-0.04,0.15) \\
\text { - } 1-2 \mathrm{~h} / \mathrm{d}: 0.07(-0.08,0.2) \\
\text { - }>2 \mathrm{~h} / \mathrm{d}: 0.28(0.06,0.50) \\
\text { p-trend = } 0.02 \text {, adjusted for Place of } \\
\text { birth, Maternal education, Socio- } \\
\text { economic status, Family size, Year of } \\
\text { birth, Year of interview }\end{array}$ \\
\hline Vandeloo (27) & Belgium, 2007 & $\mathrm{n}=1146$ & $\begin{array}{l}\text { No sport vs. Some sport (Ref) } \\
\text { Hazard Ratio }(95 \% \mathrm{Cl}) \text { : Time } \\
\text { to menarche (year) } \\
1.28(1.054,1.573) \\
\mathrm{p}=0.013\end{array}$ & \\
\hline Papadimitriou (28) & Greece, 2008 & $n=750$ & $\begin{array}{l}\text { Active vs. Passive } \\
\text { Mean difference (SE), AAM } \\
\text { (year) } \\
0.09(0.09) \\
\text { T-test: } p=0.3\end{array}$ & \\
\hline Morris (24) & UK, 2010 & $n=81438$ & & $\begin{array}{l}\text { Linear regression coefficient }(95 \% \mathrm{Cl}) \text { : } \\
\text { AAM (years) } \\
0.0983(0.065,0.133) \text { per } 10 \mathrm{~h} / \mathrm{wk} \\
\text { PA } \\
\text { P < } 0.01 \text {, adjusted for Ethnicity, } \\
\text { Weight, Height, Number of siblings, } \\
\text { Birth order, Maternal age, Twinning, } \\
\text { Exposure to preeclampsia, } \\
\text { Birthweight }\end{array}$ \\
\hline
\end{tabular}

$\mathrm{PA}=$ Physical activity, $\mathrm{AAM}=$ Age at menarche, Ref $=$ Reference group .

differences in diet, finding a significant positive association between PA duration and menarche (22). Even the RCT provides limited evidence for a direct effect of PA on menarche timing because it tested a multicomponent intervention that targeted diet as well as PA. Post hoc modelling by those study authors estimated that change in PA accounted for $1 / 3$ of the intervention effect on menarche timing (18).

Other limitations of the included studies deserve mention and are informative for the design of future studies. Associations with energy expenditure are highly likely to be confounded by the established strong relationships between body weight and total energy expenditure (positive), and between body weight and AAM (negative). Therefore, in studies of energy expenditure, adjustment for body weight is essential. Cohort studies (one PCS and two
HCS) that tested binary PA groupings failed to describe the criteria used to define these groupings $(23,27,28)$. Finally, it is important to highlight the appreciable error in estimating PA. No study used an objective measure of PA, and the limitations of self-reported PA, for example social desirability bias, are well-recognised. Merzenich et al. (22) reported a correlation coefficient of only 0.3 between energy expenditure assessed by questionnaire versus by seven-day diary. To improve reliability, they restricted their analysis to individuals who reported consistent PA durations between instruments, also their analysis controlled for the relevant confounders diet and per cent body fat, and they found a significant association between PA duration and timing of menarche (22). Moisan et al. (19) found no significant association in analyses adjusting only for age and mother's AAM. Both studies categorised PA duration into 


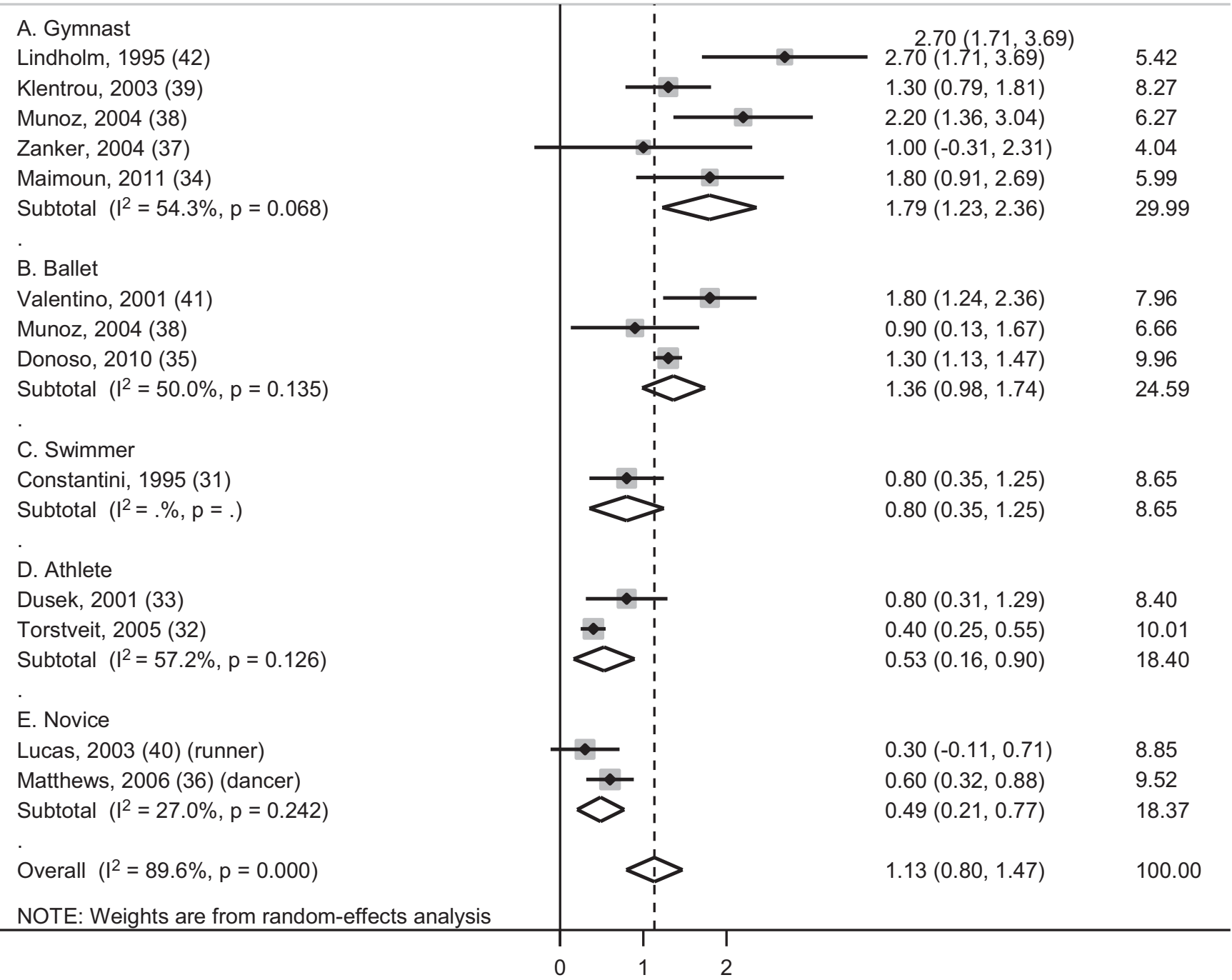

Figure 2 Forest plot showing mean differences in age at menarche (years) in athletes compared to nonathletes, categorised by type of athlete. Data are from inversevariance-weighted random-effects meta-analysis.

quartiles $(19,22)$, but these groups might not be directly comparable, and they were generated from different populations (Germany, Canada). Finally, there was considerable variation in exposure assessments, populations considered and statistical analyses. Furthermore, even within groups of relatively consistent study design and exposure, different analytical strategies (i.e. categorisation of exposure status, choice of statistical model and adjustment for confounders) precluded direct comparison of effect estimates. As a result, meta-analysis was determined to be neither feasible nor appropriate.

It has been proposed that the effect of PA on puberty timing is mediated by body composition, specifically adipose tissue (30). The adipocyte-secreted hormone, leptin, is known to stimulate the reproductive hormone axis and trigger reproductive maturation in women (25).
Conversely, low leptin levels may mediate the effects of negative energy balance on delaying/disrupting menstruation via suppression of $\mathrm{GnRH}$ pulsatility (31). In this regard, nutritional restriction is a key potential confounder in the athlete/nonathlete studies, as thinness may confer advantages in several sports (32). Additionally, a selection effect, whereby individuals predisposed to thinness and later pubertal maturation are more likely to become and succeed as athletes, is also possible (32). However, the observation of significant differences in AAM in athletes engaged in sports not advantaged by thinness (e.g. swimming, basketball) indicates that nutritional deprivation is unlikely to explain the entirety of the observed associations (31,33). Furthermore, some population-based studies reported associations with PA that were independent of body weight. For example, Morris 
et al. (24) found that adjustment for childhood weight did not attenuate the association between PA and AAM. However, it is possible that changes in body composition (i.e. adiposity) occurred without impacting overall weight. Furthermore, in the identified RCT, change in PA appeared to mediate the intervention effect separately from changes in BMI or skinfold thickness (18). Additionally, the multivariate analysis reported by Merzenich et al. (22) revealed an independent effect of PA, when adjusted for percentage body fat. These results indicate that PA might exert some effects on AAM through pathways independent of adiposity.

In conclusion, this systematic review synthesises the published evidence for the association between PA and AAM. Our meta-analysis indicates a significant delay in menarche, of roughly one year, in athletes compared to controls. Most studies were of elite athletes; however, studies of novice athletes also showed a significant delay of around half a year. Supportive evidence of an effect of PA on delaying menarche was identified from one RCT. However, lack of intervention specificity in the RCT, and confounding by diet and other factors, and potential large errors in PA measurement in the observational cohorts limit estimation of the true effect size. Overall, the strength of evidence based on reported general population samples is low. Future studies are needed to clarify the magnitude and nature of the effect of childhood PA on the timing of menarche in the general population.

\section{FUNDING}

$\mathrm{KKO}$ and SB are supported by the Medical Research Council (Unit programmes: MC_UU_12015/2 and MC_UU_12015/3).

\section{CONFLICT OF INTEREST}

No conflicts of interest.

\section{References}

1. Copeland W, Shanahan L, Miller S, Costello EJ, Angold A, Maughan B. Outcomes of early pubertal timing in young women: a prospective population-based study. Am J Psychiatry 2010; $167: 1218-25$

2. Graber JA, Seeley JR, Brooks-Gunn J, Lewinsohn PM. Is pubertal timing associated with psychopathology in young adulthood? I Am Acad Child Adolesc Psychiatry 2004; 43: 718-26.

3. Mendle J, Turkheimer E, Emery RE. Detrimental psychological outcomes associated with early pubertal timing in adolescent girls. Dev Rev 2007; 27: 151-71.

4. Lakshman R, Forouhi NG, Sharp SJ, Luben R, Bingham SA, Khaw K-T, et al. Early age at menarche associated with cardiovascular disease and mortality. J Clin Endocrinol Metab 2009; 94: 4953-60.

5. Lakshman R, Forouhi N, Luben R, Bingham S, Khaw K, Wareham N, et al. Association between age at menarche and risk of diabetes in adults: results from the EPIC-Norfolk cohort study. Diabetologia 2008; 51: 781-6.
6. Hsieh C-C, Trichopoulos D, Katsouyanni K, Yuasa S. Age at menarche, age at menopause, height and obesity as risk factors for breast cancer: associations and interactions in an international case-control study. Int J Cancer 1990; 46: 796800

7. Jacobsen BK, Heuch I, Kvåle G, Kvale G. Association of low age at menarche with increased all-cause mortality: a 37-year follow-up of 61,319 Norwegian women. Am J Epidemiol 2007; 166: 1431-7.

8. Bosetti C, Tavani A, Negri E, Trichopoulos D, La Vecchia C. Reliability of data on medical conditions, menstrual and reproductive history provided by hospital controls. J Clin Epidemiol 2001; 54: 902-6.

9. Koo MM, Rohan TE. Accuracy of short-term recall of age at menarche. Ann Hum Biol 1997; 24: 61-4.

10. Must A, Phillips SM, Naumova EN, Blum M, Harris S, Dawson-Hughes B, et al. Recall of early menstrual history and menarcheal body size: after 30 years, how well do women remember? Am J Epidemiol 2002; 155: 672-9.

11. Morris DH, Jones ME, Schoemaker MJ, Ashworth A, Swerdlow AJ. Secular trends in age at menarche in women in the UK born 1908-93: results from the Breakthrough Generations Study. Paediatr Perinat Epidemiol 2011; 25: 394-400.

12. Day FR, Thompson DJ, Helgason H, Chasman DI, Finucane H, Sulem P, et al. Genomic analyses identify hundreds of variants associated with age at menarche and support a role for puberty timing in cancer risk. Nat Genet 2017; 49: 834-41.

13. Kelly Y, Zilanawala A, Sacker A, Hiatt R, Viner R. Early puberty in 11-year-old girls: Millennium Cohort Study findings. Arch Dis Child 2017; 102: 232-7.

14. Yermachenko A, Dvornyk V. Nongenetic determinants of age at menarche: a systematic review. Biomed Res Int 2014; 2014 371583.

15. Dumith SC, Gigante DP, Domingues MR, Hallal PC, Menezes AMB, Kohl HW 3rd. Predictors of physical activity change during adolescence: a 3.5-year follow-up. Public Health Nutr 2012; 15: 2237-45.

16. Baker BL, Birch LL, Trost SG, Davison KK. Advanced pubertal status at age 11 and lower physical activity in adolescent girls. J Pediatr 2007; 151: 488-93.

17. Labbrozzi D, Robazza C, Bertollo M, Bucci I, Bortoli L. Pubertal development, physical self-perception, and motivation toward physical activity in girls. J Adolesc 2013; 36: 759-65.

18. Chavarro JE, Peterson KE, Sobol AM, Wiecha JL, Gortmaker SL. Effects of a school-based obesity-prevention intervention on menarche (United States). Cancer Causes Control 2005; 16 : 1245-52.

19. Moisan J, Meyer F, Gingras S. Leisure physical activity and age at menarche. Med Sci Sports Exerc 1991; 23: 1170-5.

20. Chie WC, Liu YH, Chi J, Wu V, Chen A. Predictive factors for early menarche in Taiwan. J Formos Med Assoc 1997; 96: 44650.

21. Koo MM, Rohan TE, Jain M, McLaughlin JR, Corey PN. A cohort study of dietary fibre intake and menarche. Public Health Nutr 2002; 5: 353-60.

22. Merzenich H, Boeing H, Wahrendorf J. Dietary fat and sports activity as determinants for age at menarche. Am J Epidemiol 1993; 138: 217-24.

23. Ramezani Tehrani F, Mirmiran P, Gholami R, Moslehi N, Azizi F. Factors influencing menarcheal age: results from the cohort of tehran lipid and glucose study. Int J Endocrinol Metab 2014; 12: e16130.

24. Morris DH, Jones ME, Schoemaker MJ, Ashworth A, Swerdlow AJ. Determinants of age at menarche in the UK: 
analyses from the Breakthrough Generations Study. Br J Cancer 2010; 103: 1760-4.

25. Chavarro J, Villamor E, Narvaez J, Hoyos A. Socio-demographic predictors of age at menarche in a group of Colombian university women. Ann Hum Biol 2004; 31: 245-57.

26. Veronesi FM, Gueresi P. Trend in menarcheal age and socioeconomic influence in Bologna (northern Italy). Ann Hum Biol 1994; 21: 187-96.

27. Vandeloo MJAM, Bruckers LM, Janssens JP. Effects of lifestyle on the onset of puberty as determinant for breast cancer. Eur J Cancer Prev 2007; 16: 17-25.

28. Papadimitriou A, Fytanidis G, Douros K, Bakoula C, Nicolaidou P, Fretzayas A. Age at menarche in contemporary Greek girls: evidence for levelling-off of the secular trend. Acta Paediatr 2008; 97: 812-5.

29. Schevchenko I, Abramov VV, Gibson PT, Omar HA. Medical supervision of young female athletes training in complex coordinational sports. Int J Adolesc Med Health 2008; 20 : 343-51.

30. Roupas ND, Georgopoulos NA. Menstrual function in sports. Hormones (Athens) 2011; 10: 104-16.

31. Constantini NW, Warren MP. Menstrual dysfunction in swimmers: a distinct entity. J Clin Endocrinol Metab 1995; 80: 2740-4.

32. Torstveit MK, Sundgot-Borgen J. Participation in leanness sports but not training volume is associated with menstrual dysfunction: a national survey of 1276 elite athletes and controls. Br J Sports Med 2005; 39: 141-7.

33. Dusek T. Influence of high intensity training on menstrual cycle disorders in athletes. Croat Med J 2001; 42: 79-82.

34. Maimoun L, Coste O, Mariano-Goulart D, Galtier F, Mura T, Philibert $\mathrm{P}$, et al. In peripubertal girls, artistic gymnastics improves areal bone mineral density and femoral bone geometry without affecting serum OPG/RANKL levels. Osteoporos Int 2011; 22: 3055-66.

35. Donoso MA, Munoz-Calvo MT, Barrios V, Garrido G, Hawkins F, Argente J. Increased circulating adiponectin levels and decreased leptin/soluble leptin receptor ratio throughout puberty in female ballet dancers: association with body composition and the delay in puberty. Eur J Endocrinol 2010; 162: 905-11.

36. Matthews BL, Bennell KL, McKay HA, Khan KM, BaxterJones ADG, Mirwald RL, et al. The influence of dance training on growth and maturation of young females: a mixed longitudinal study. Ann Hum Biol 2006; 33: 342-56.

37. Zanker CL, Osborne C, Cooke CB, Oldroyd B, Truscott JG. Bone density, body composition and menstrual history of sedentary female former gymnasts, aged 20-32 years. Osteoporos Int 2004; 15: 145-54.

38. Munoz MT, de la Piedra C, Barrios V, Garrido G, Argente J. Changes in bone density and bone markers in rhythmic gymnasts and ballet dancers: implications for puberty and leptin levels. Eur J Endocrinol 2004; 151: 491-6.

39. Klentrou P, Plyley M. Onset of puberty, menstrual frequency, and body fat in elite rhythmic gymnasts compared with normal controls. Br J Sports Med 2003; 37: 490-4.

40. Lucas JA, Lucas PR, Vogel S, Gamble GD, Evans MC, Reid IR. Effect of sub-elite competitive running on bone density, body composition and sexual maturity of adolescent females. Osteoporos Int 2003; 14: 848-56.

41. Valentino R, Savastano S, Tommaselli AP, D'Amore G, Dorato M, Lombardi G. The influence of intense ballet training on trabecular bone mass, hormone status, and gonadotropin structure in young women. J Clin Endocrinol Metab 2001; 86: 4674-8.

42. Lindholm C, Hagenfeldt K, Ringertz H. Bone mineral content of young female former gymnasts. Acta Paediatr 1995; 84: 1109-12.

\section{SUPPORTING INFORMATION}

Additional Supporting Information may be found online in the Supporting Information section at the end of the article.

Table S1 Population studies exclusion criteria on full text review.

Table S2 Prospective cohort studies: summary of methods.

Table S3 Historical cohort studies (cross sectional): summary of methods.

Table S4 Prospective cohort population studies, quality assessment.

Table S5 Cross-sectional population studies, quality assessment.

Table S6 Athlete/non-athlete studies: summary of methods. 